\title{
The healthcare experience of prostate cancer patients: exploring the intersection of age and gender
}

\author{
By LOUIS BRAVERMAN*
}

\begin{abstract}
Although researchers have conducted extensive studies of the psychosocial impacts of prostate cancer and its treatment on men's bodies, masculinity and sexuality, little attention has been devoted to the intersection of gender and age in the healthcare experience of this illness. Based on data collected through direct observation in four French public hospitals, and 65 semi-directive interviews with prostate cancer patients, their relatives and healthcare professionals, this article aims to examine how age and gender shape care pathways. We argue that combining the concept of hegemonic masculinity with an intersectional approach may provide an adequate theoretical framework for analysing the plurality of men's prostate cancer healthcare experience. Four steps of the patient care process are successively analysed to assess how the patient experience of illness may be influenced by power relations that interact with individual characteristics: screening, diagnosis, treatment and follow-up care.
\end{abstract}

Keywords: ageing, gender, illness experience, intersectional analysis, masculinities, prostate cancer.

*Louis Braverman, Laboratoire d'Économie de Dauphine - Laboratoire d'Économie et de Gestion des Organisations de Santé (LEDa-LEGOS), Université Paris-Dauphine - PSL, Paris, France 
International Journal of Ageing and Later Life

\section{Introduction}

At global level, prostate cancer is one of the commonest male cancers. Each year, around 1,100,000 new cases are diagnosed, and 300,000 deaths attributed to it, worldwide (Tao et al. 2015). This extremely common cancer affects an ageing population. In France - the country in which the study underlying this article was conducted - the median age at diagnosis of prostate cancer is just below 70 years (Grosclaude et al. 2015). Many patients thus require both geriatric and urologic evaluation to define a personalised cancer treatment that takes into account comorbidities, frailty and other individual circumstances that may be related to ageing.

Although the challenges of treating prostate cancer in the elderly population have long been discussed and are now well documented (Blank \& Bellizzi 2008; Droz et al. 2010, 2017; Grummet et al. 2017; Jha et al. 2014; Terret et al. 2004), the gerontology and geriatric literature avoids considering how masculinities shape (and are shaped by) men's experience of illness. Taking into account gender dynamics, social science studies have led the way in extending and deepening knowledge about how men manage prostate cancer, by examining experiences shared by patients in support groups (Arrington 2000; Cecil et al. 2010; Oliffe et al. 2010); doctor-patient communication (Arrington 2004; Oliffe 2007) and effects on personal identity (Arrington 2008; Broom 2004; Chapple \& Ziebland 2002; Gray et al. 2002; Kelly 2009; Oliffe 2006, 2011; Stansbury et al. 2003; Wall \& Kristjanson 2005).

Despite the depth of this literature, the interlocking systems of privilege and oppression (sexism, classism, racism, ageism, homophobia, etc.) at the micro-level of men's experience remain understudied. Although some works stress the intersection of different power relations in their analyses, and certain notable exceptions tackle the experience of prostate cancer for homosexual men (Blank 2005; Dowsett 2008; Filiault et al. 2008) and racialised men (Gray et al. 2005; Rivas et al. 2016), the intersectional nature of subjectivities (Collins \& Bilge 2016) is underexplored in the existing literature.

As prostate cancer mainly strikes older men, this article outlines the importance of conducting a systematic examination of how age and gender intersect, to better document the lived experience of men having the condition. We therefore mobilise an intersectional analysis that 
aims to explore how age and gender combine with class, race/ethnicity and sexual orientation to influence health. Also, while the effects of treatments are well documented, prostate cancer care pathways are not as well understood. This article therefore aims to identify and characterise how gender and age shape the patient cancer healthcare experience. To this end, four important steps in the patient care process are analysed: screening, diagnosis, treatment and follow-up care. These steps were chosen to better assess how the patient healthcare trajectory may be influenced by power relations. These steps do not, however, represent linear stages having specific roles or statuses, nor do they necessarily imply a limited sequence of events in a patient trajectory, because we consider patient trajectories to be shaped and managed through ongoing interactions of actors (Corbin \& Strauss 1988).

\section{Theoretical frameworks}

This article suggests that combining the concept of hegemonic masculinity with an intersectional approach may offer an adequate theoretical tool for analysing the complexities of differences and hierarchic power relations between men with prostate cancer, in the context of care.

Connell defines hegemonic masculinity as "the configuration of gender practice which embodies the currently accepted answer to the problem of the legitimacy of patriarchy, which guarantees (or is taken to guarantee) the dominant position of men and the subordination of women" (Connell 2005 [1995] :77). For the Australian sociologist, hegemonic masculinity is a kind of normative ideal that may very well be the prerogative of a handful of men - or none at all - but that requires each man to position himself in relation to it. The concept of hegemonic masculinity is therefore a tool designed to study patriarchy and hierarchical relationships between men, at once. Connell identifies three configurations of masculinities hierarchically subordinated to hegemonic masculinity: complicity, marginalisation and subordination.

Although the recognition of a plurality of masculinities and their hierarchisation is essential to understanding gender relations, the concept of hegemonic masculinity is the focus of various criticisms (Demetriou 2001; Jefferson 2002; Wetherell \& Edley 1999). One important criticism is made 
International Journal of Ageing and Later Life

by Christensen and Jensen (2014), who argue that the typology proposed by Connell makes it possible to differentiate between privileged positions and other (subordinate) positions, yet without completely deconstructing the production of these categories. For Christensen and Jensen, the intersectional approach (understood as the study of positions at the intersection of multiple power relations) represents a useful alternative approach to the analysis of masculinities. Firstly, the intersectional approach suggests thinking about the co-construction of gender with other categories and the articulation of systems of oppression, which is precisely what the concept of hegemonic masculinity, as it is mainly used, does not allow us to do. Secondly, the intersectional framework is a useful tool for deconstructing processes that lead to the establishment of some masculinities at the top of the gender order and others at the margins because it suggests describing patterns of domination and resistance according to a dynamic design.

Combining hegemonic masculinity with intersectionality also provides a framework for the consideration of age as a useful category of analysis. Indeed, age can be understood not only as a biological marker of ageing but also as a social organising principle, and several research papers in the field of ageing studies (Calasanti 2003; Calasanti \& Slevin 2006; McMullin \& Marshall 2001) emphasise their own analysis of how age intersects with such power relations as gender, class, race, disability and sexuality. However, adopting an intersectional perspective often leads to a bias towards analysing the articulation of certain power relations, to the detriment of others. Because it is empirically difficult (if not impossible) to take account of how the various categories of analysis are interwoven, this is an inherent methodological limitation of intersectionality theorisations. Given our field of investigation, we will focus on analysing the articulation of age, gender and class power relations at the expense, in particular, of sexual orientation and ethnicity.

\section{Materials and methods}

This article relies on data collected through direct observation within the hospital setting because this investigative technique allows direct access to events and situations. Observations were made over a period of 5 months, at four different hospitals. All these hospitals are public, though 
they vary in size and location across France. The work of healthcare professionals in both urology and radiotherapy units was monitored over a prolonged period. Using a semi-structured template, notes were taken in a range of settings: medical consultations, multidisciplinary meetings, biopsies, surgical operations, medical team meetings, nursing care, sexology consultations, the pre-radiotherapy tracking phase, doctors' visits to hospitalised patients and so on. Field notes typically include details of the doctor-patient relationship, a description of care, informal conversations with health professionals and patients, analytical memos, context and recording of personal experience. Notes were analysed inductively.

In addition, 65 semi-structured interviews were recorded and transcribed. Fifty-five interviews were conducted with prostate cancer patients. The other ten interviews were with healthcare professionals (doctors, nurses, social worker, the coordinator of a regional cancer care network, etc.). In all of these cases, interviewees were recruited from different study sites. Most often, participants were directly asked, following a medical consultation, whether they would agree to take part in a sociological study. In some cases, they were initially approached by phone. A purposive sampling approach was used.

All participants are heterosexual. The men interviewed were diagnosed at various stages, and benefited from the main treatments available (surgery, radiotherapy, brachytherapy, ${ }^{1}$ ultrasound, chemotherapy, hormone therapy and active monitoring). Some participants had been living with the illness for a long time (more than 12 years, for some); others were recently diagnosed (at least 1 week ago). The average age of interviewees was 69 years and 8 months, the youngest being 53 and the oldest being 92. Most participants were therefore retirees at the time of their interviews. However, their trajectories and social statuses were fairly diverse. Even if the large majority of the men in the sample belong to the upper-middle or middle classes, twelve of the 55 participants belong to the working class; two were born outside of France. Religious beliefs were not systematically asked about.

Interviews with the men facing prostate cancer took place outside of the medical environment, most often in their homes. The interviewee's spouse or life partner was present in a third of cases. An opening question invited respondents to tell the story of their illness: "Can you tell me about your experience?". In response to this invitation, participants were 
International Journal of Ageing and Later Life

free to address the various aspects as they chose, whether or not this was in chronological order. Follow-up questions were sometimes asked, enabling a deeper dive into the discourse while ensuring that the interview followed the structure chosen by the respondent.

The interviews were analysed in two stages. Firstly, an initial analysis per interview was carried out. Its purpose was to report, for each interview, on the meaning that men ascribe to their experience. Then, a thematic analysis attempted to cross-reference material referring to the same theme, from one interview to another. Data coding was based on an inductive approach, using NVivo software.

This research was supported by the French National Cancer Institute. No ethical approval for the study was required; a priori scrutiny by ethics committees of research projects in social sciences is exceptional in France, unlike in the United States and Canada (Vassy \& Keller 2008). However, written approval from both hospital directors and heads of units was obtained prior to carrying out the fieldwork. Health professionals in the various fields were also informed of the study's implementation. Free and informed consent was also obtained from all participants. Names have been changed to protect the anonymity of respondents.

\section{Screening}

Prostate cancer screening relies on two main elements: testing for Prostate-Specific Antigen (PSA) and digital rectal examination. In most participant narratives, the screening experience is shaped by gender and age: the PSA test starting around ages 45-55, like the digital rectal examination that is also sometime associated as an affront to masculinity.

\section{The ageing body as seen at molecular level}

PSA is a biological marker that is used to screen for prostate cancer as well as to determine the effectiveness of various treatments, and track the progression of the illness. Although this biomarker has been the subject of intense controversy (Faulkner 2010), it is still a central element in prostate cancer care. PSA tests, which require a blood sample to be taken, are common procedures. In France, it is estimated that about $48 \%$ of men aged $40+$ underwent PSA testing between 2013 and 2015 (Tuppin et al. 2016). 
As PSA testing is at the heart of screening practice, it is particularly helpful in classifying men into groups because it separates at-risk bodies from healthy bodies. Indeed, screenings are not recommended to all men equally. Epidemiologists have identified three main risk factors, which help distinguish between populations: age, family history, and geographical and ethnic origin. The Association Française d'Urologie (AFU - French Urology Association) therefore recommends that men begin cancer screenings (digital rectal examination and PSA tests) at the age of 50 where no risk factors are present, and at age 45 for those with a family history of the illness, or for men of African or Caribbean origin (Rozet et al. 2016). Beyond the age of 75, PSA testing is no longer recommended, but the digital rectal examination continues to be considered necessary to the diagnosis of any clinically expressed prostate cancer (Rozet et al. 2016). In other words, biomedical recommendations sort those who are at risk from those who are not (at least in theory), through the use of a statistical assessment of the body that originates at the intersection of the sex, age, race and family history risk factors.

Categorisations relying on epidemiological knowledge have significant effects on individuals because being "at-risk for prostate cancer" implies real consequences for men. Firstly, it implies a need to take responsibility, even a duty, in relation to this specific risk. Indeed, health has now become an individual imperative as well as a moral and social obligation (Crawford 1980). The prevention campaigns encouraging men to take regular PSA tests once they are in their 50s exemplify this phenomenon. In addition, being "at-risk" identifies men's bodies as vulnerable. Gillespie (2012) argues that the absence of symptoms linked to a high PSA heightens men's feeling of vulnerability because it is impossible to determine the risk of cancer without taking additional tests. Moreover, these additional diagnostic investigations (ultimately, fresh PSA testing, digital rectal examination, magnetic resonance imaging [MRI], biopsy, scan) only add to the already-present uncertainty (Evans et al. 2007). Indeed, a sudden or gradual rise in PSA level often sees at-risk men being drawn into a complicated medical cycle. Patients frequently experience a loss of control over their own trajectory at the moment in which their PSA level becomes high because it is on the basis of this event that the medical machine goes into overdrive (Oliffe 2006). 
International Journal of Ageing and Later Life

Thus, the first PSA measurements (taken around age 50) are often considered by patients as the starting point for their cancer experience, as in the example given below:

Jean-Paul: So, like many other French men aged 50 to 60, I was having PSA tests every two years. I was at 2 - normal. And then in November of last year, suddenly I was at 6, boom. My general practitioner told me "it needs keeping an eye on", so three months later he tested my PSA again, and I was at 7.5 - red alert. He said, "I'm sending you to see a urologist". Before sending me to the urologist, he sent me for an MRI of the prostate.

Q.: Okay.

Jean-Paul: Nothing showed up on the MRI. Same thing for the digital rectal examination. [...] So, with a level of 6 that had gone up to 7.5, I went to see Dr Grandon (the urologist) and he said, "We need to do a biopsy". So he took the biopsy. I think my treatment was absolutely classic. And the biopsy showed that I did have the start of a cancer.

(Jean-Paul, 62, retired agronomy researcher. Diagnosed in 2013, surgery)

Jean-Paul offers a good explanation of how, as for a great many patients, a series of tests begins with the first PSA checks at 50 and leads all the way to a discovery of cancer. His words also show the importance of the molecular level in defining at-risk bodies. However, the construction of masculinities in relation to prostate cancer management can also be examined from another aspect of screening: the digital rectal examination.

\section{Male resistance to digital rectal examination}

For men, digital rectal examinations are a must for the prevention, screening and monitoring of several prostate diseases. This examination consists of inserting a gloved and lubricated finger into the patient's rectum, to palpate the prostate. Digital rectal examinations are not supposed to be painful. Nonetheless, prevention campaigns regularly point out that this examination is an obstacle to prostate cancer screening.

Indeed, previous works have documented men's reluctance to undergo digital rectal examination (Furlan et al. 2008; Macias et al. 2000; Nagler et al. 2005). This attitude can be multifactorial: fear of the illness, disgust 
at the idea of pollution (Douglas 1966), denial of potential vulnerability and so on. Yet, it seems particularly important to us to highlight the incompatibility of this examination with the ideal of hegemonic masculinity. It suggests that this examination does not allow the patient to perform his masculinity because it involves a passive role and penetration of the body, which is, in our heteropatriarchal societies, perceived as emasculating (Bourdieu 1998). In other words, male resistance to digital rectal examinations is tied to radically distancing oneself from "subordinated masculinity" (Connell 2005 [1995]), that is, gender performances that evoke the behaviours of men suspected of being effeminate - gay men especially.

Nevertheless, previous literature has noted that men's responses to digital rectal examination of the prostate vary according to class and race (Dale et al. 1999; Kenerson 2010). Kenerson (2010: 60) points out that for African-American men, the cost of screening is the main obstacle. Focusing analysis on class relations thus reveals the hierarchies existing between different masculinities. It is because they embody a "marginalized masculinity" (Connell 2005 [1995]) - in other words, a form of masculinity that is unable to conform to hegemonic masculinity because of their positioning with class relations or the relations of racialisation - that men from dominated social groups show stronger aversion to digital rectal examination.

Age also plays a considerable role in men's response to digital rectal examination. As men move into the segment of the population that is "at-risk for prostate cancer", men over the age of 50 often see digital rectal examinations as a necessary process tied to ageing. For example, Didier, aged 53, said "We're not kids anymore!" when describing his own attitude and that of his friends towards digital rectal examinations. A nurse also said that he was going to start measuring the level of PSA in his blood and getting digital rectal examinations the following year, once he had passed the age of 50. As Calasanti has shown, age is of crucial importance in defining men's health practices because men can develop a sense of responsibility that can lead to improved self-care as they get older (Calasanti et al. 2013).

Fear of serious illness and the risk of cancer-induced vulnerability also serve to counteract the negative effects often associated with digital 
International Journal of Ageing and Later Life

rectal examinations. The fact that digital rectal examination is a medical procedure performed by professionals contributes a great deal to men's acceptance of it. Furthermore, Philippe's testimony echoes that of several other interviewees for whom the digital rectal examination has become "normal" or "routine" with ageing:

Philippe: I thought it was normal, it doesn't surprise me. Maybe I was a bit shocked the first time, but no.

Q.: Why do you think that is?

Philippe: You know the doctor needs to... when he can take a photo from inside, he'll do that - but I imagine there are some things that he needs to feel... it's never bothered me.

Q.: You don't think it's something that impacts your manhood, your masculinity?

Philippe: No, not at all. I think you have to be realistic in life. And I also think you should be glad the doctor is looking to see if there's anything going on. Looking at it that way, no, not at all.

(Philippe, aged 90, retired postal worker. Diagnosed in 2011, hormone therapy)

Digital rectal examinations are most often accepted out of medical necessity, as was the case for this man. Our results thus contribute to challenging assumptions of help-seeking as essentially problematic for men in western society (Noone \& Stephens 2008; Wenger \& Oliffe 2014). However, the medical necessity that justifies the digital rectal examination does not prevent those men still closely identified with ideals of hegemonic masculinity from feeling ill at ease. Bernard, a former naval officer, offers a good example of this:

Q.: In terms of the examinations prior to discovery of the illness, I often ask about the digital rectal examination. How did that go?

Bernard: It's a bit embarrassing.

Q.: In what way? Is it because it's painful?

Bernard: It's more of, um... a masculine question, you know. Having a finger where it doesn't belong, I don't enjoy that. Well, when it's in a medical context, you accept it. You rise above it.

Q.: So it's seen as something that affects masculinity?

Bernard: Exactly. But it's necessary. So you put up with it, you grit your teeth. 
Q.: But it isn't what would have put you off getting the examination?

Bernard: No, that wouldn't have stopped me. No, no. If it has to be... I go. I'd say almost reluctantly, but I go because I know that it's my health at stake.

(Bernard, aged 68, retired naval officer. Diagnosed in 2013, surgery)

It should be mentioned that Bernard spent his entire career in an institution that inculcates male domination and involves distancing from the feminine (Devreux 1997). It is only when faced with the risk to his health that his aversion to digital rectal examination can be, at least partially, overcome. Lastly, consideration of masculinities as plural also implies consideration of a range of practices, as well as the emotional labour of prostate cancer screening. Our study of male resistance to the digital rectal examination thus supports the argument that men's attitudes towards help-seeking and self-care are linked to gender order, as well as to other power relations (Parent et al. 2018). Nevertheless, it is worth noting that various forms of medical examinations may be associated with various forms of disgust, shame or feeling ill at ease, and that these emotions may not only be linked with masculinity, but may also be part of the way in which power is exercised through the medicalisation of the body.

\section{Diagnosis}

Although each patient trajectory begins differently, we argue that age and gender strongly shape the experience of prostate cancer diagnosis. This premise has been tested by distinguishing between two levels of analysis: (1) of institutions, drawing on social frameworks that participate in defining the organisation of care and (ii) of interactions, on the basis of studying the doctor-patient relationship and the effects an announcement of cancer can have on subjectivities.

\section{The announcement protocol}

In France, the law controls how cancer diagnoses are given. The 4 March 2002 law relative to the rights of patients and the quality of the healthcare system gave everyone the rights to be informed of the state of their health. Institutional reforms were also aimed at improving how cancer diagnoses 
International Journal of Ageing and Later Life

were given. An announcement protocol is now required for healthcare institutions to obtain accreditation to treat cancer patients. Measure 40 of the first "Cancer Plan" (2003-2007) set out four key elements upon which the announcement protocol was based: announcement of the diagnosis and presentation of the treatment plan by the doctor; appointments with health professionals; access to supportive care and communication with the general practitioner.

Informing someone that they have a serious illness is still a delicate task. Specialists such as urologists and oncologists are still often described by patients as lacking empathy. In the same way, the nurses involved in the diagnosis process may emphasise the emotional labour inherent to their job or - on the contrary - seek recognition of their technical competence. The diagnosis process thus remains affected by the devaluation of care, which is itself strongly influenced by the gendered division of emotion (Tronto 1993).

In addition, implementation of the announcement protocol is limited by social representations that are attached to pathologies. Prostate cancer, for example, carries taboos tied to masculinity (Arrington 2004; Broom 2004; Cecil et al. 2010; Oliffe 2011 [2009]; Zanchetta et al. 2007). Therefore, when I met a nurse charged with delivering diagnoses and coordinating follow-up cancer care in a university medical centre and asked her whether she regularly speaks with men who have prostate cancer, her response was categorical:

It's true that I don't see many men with prostate cancer. Why... well it affects men, it has to do with their virility and I feel that we talk even less to men than we do to women, because of that.

(Field diary, 29/09/2014)

A statistical study of life 2 years after a cancer diagnosis (INCa 2014) shows that men and elderly people are far less likely than women or younger adults to be advised to consult a psychologist, nurse or social worker when they are informed of their condition. The fact that health professionals often share stereotypical beliefs concerning gender and age largely explains this unequal treatment, which disproportionately impacts prostate cancer patients. 
Healthcare experience of prostate cancer patients

\section{Reaction to diagnosis}

The beginning of the cancer trajectory is fractured over time, and the initial diagnosis must be thought of as a process rather than an isolated moment (Schaepe 2011). Nevertheless, men with prostate cancer often learn of their condition during a medical consultation - most often with a urologist. Given by a doctor, the diagnosis is a performative linguistic act (Austin 1975) in the sense that it gives a new status to the person in whom an anomaly has been discovered: the healthy (or at-risk) individual becomes sick. This shift from normal to pathological, via what a doctor says, is all the starker because of the fact that the patient being informed of the diagnosis is often asymptomatic. Moreover, most participants report the shock brought on by the announcement. "It's true that it's a shock", said Marc (aged 60, engineer. Diagnosed in 2012, surgery). "On the spot, it shook me up. They tell you it's cancerous, it is a bit of a shock", said Alain (aged 68, retired plumber. Diagnosed in 2012, surgery). Jean-Jacques stated that it "knocked him for six" (Jean-Jacques, aged 62, retired agronomy researcher. Diagnosed in 2013, surgery). Another patient described it as like "being hit on the head with a hammer" (René, aged 75, retired insurance manager. Diagnosed in 2012, surgery).

However, Bury's (1982) insight that a diagnosis of chronic illness is often experienced as "biographical disruption" fails to fully acknowledge the complexity of the early stages of prostate cancer. Our study shows that a prostate cancer diagnosis neither necessarily disrupts the structure of everyday life, nor comes as a shock to the patient. This phenomenon can be explained by several factors, three of which are of particular importance: the patient's idea of how serious the cancer is, his socialisation as a man, and his age and biographical trajectory. These three factors are often linked - and indeed sometimes emerge in the course of a single interview - but to understand their logic, it seems important to discuss them in turn.

Firstly, the seriousness of the illness - and to a greater extent the patient's own perception of it - plays a crucial role in the impact of the diagnosis. Although it is true that for many people cancer is synonymous with death, this is now less often the case due to progress made in biomedicine. In France, the 5-year survival rate for men with prostate cancer is now over 90\% (INCa 2017), and many people are aware of this trend. 
International Journal of Ageing and Later Life

The lack of trauma experienced by Marius after receiving his cancer diagnosis is not as unusual as common knowledge and medical doxa would have one believe:

Q.: How did you take the news?

Marius: Very well.

Q.: It wasn't given to you too harshly?

Marius: Not at all. And knowing that prostate cancer isn't... there's been a lot of progress. It wasn't some other cancer. And anyway, when you have cancer, you have cancer, what do you want me to say? (laughs). Me, I never worried about it.

(Marius, aged 68, retired cook. Diagnosed in 2010, surgery)

Using the same argument as Marius, many patients minimise their prostate cancer diagnosis because the tumour is not aggressive, and their life expectancy is not perceived to be threatened. Comparing his prostate cancer with the liver cancer that killed his brother, Robert says he was not "traumatised" by learning of his own illness, which he considers "benign" (aged 70, retired physiotherapist. Diagnosed in 2013, ultrasound).

Secondly, a prostate cancer diagnosis may also be an occasion for gender performance. Indeed, conforming to ideals of hegemonic masculinity requires distancing oneself from any sign of weakness or fragility, and accepting the diagnosis without showing any emotion. Bernard, a retired car worker, explained: he did not break down after the doctor told him he had cancer: "No, I didn't take it hard, not like how some people would maybe start blubbering, I don't know". Bernard did not "blubber" (cry) and took the news "like a man", as we might say, because acting according to the codes of hegemonic masculinity requires that what is socially perceived as weakness must not be shown. The use of the term "blubber" also serves to put down this reaction in others. Bernard's follow-up comments reinforce the idea of a performance of masculinity while receiving the diagnosis because immediately afterwards he added a remark about his desire to still be able to have erections: "I told the doctor 'Listen, you telling me this now, it's no big deal, but I still want to get hard from time to time'. I let him know like that" (Bernard, aged 65, retired car worker. Diagnosed in 2013, surgery). 
Thirdly, age is a factor that plays an important role in experiencing a prostate cancer diagnosis. Men who are affected may have already begun pulling back from a number of activities. They may have other medical conditions or think of themselves as growing old and going downhill, which can potentially lead them to minimise the prostate cancer diagnosis. Philippe's words support this argument:

I was prepped a little bit by my doctor, who told me: "I've been monitoring you for a long time already, with the PSA tests. You have cancer, but it isn't at a really advanced stage", and besides that, at the time I was 88 years old, so he told me at that age, it advances much more slowly. So, with all that, I never felt any worry when they told me I had cancer.

(Philippe, aged 90, retired postmaster. Diagnosed in 2011, hormone therapy)

For Philippe, his advanced age, along with the absence of any immediate threat attributed by him to his cancer, is inextricably linked to the experience of diagnosis. As we have noted, the diagnosis of prostate cancer does not necessarily disrupt the structure of everyday life and this phenomenon can be explained by several factors that are often interrelated. Paying attention to such factors leads to a nuanced description of cancer diagnosis, both as a marker of a destructive disease and as a starting point for identity reconstruction work (Balmer et al. 2015; Liamputtong \& Suwankhong 2015).

\section{Treatment and follow-up care}

The treatment and supportive care that prostate cancer patients may benefit from are also embedded within systems of inequality. To support this hypothesis, we begin by arguing that the objective of providing person-centred care for all men with prostate cancer is hampered by the ageism and heteronormativity of healthcare institutions and professionals. Then, we argue that sexual health in prostate cancer care reproduces both age and gender domination.

\section{Challenges in providing patient-centred care}

In France, as in many other countries, the development of patient-centred cancer care is identified as a top priority action towards improving the 
International Journal of Ageing and Later Life

quality of care. Indeed, the 3rd Cancer Plan (2014-2019) makes direct reference to patient-centred care. However, it is far from simple to take into account all the needs of the person and their loved ones while simultaneously respecting their values and preferences and increasing their involvement in decisions that affect them. One of the difficulties that arises is the potential conflict between patient-centred care and Evidence-Based Medicine (Bensig 2000). When it comes to developing person-centred care for prostate cancer patients, we argue that this objective is also rendered difficult by inadequate recognition of the plurality of masculinities within institutions and among healthcare professionals.

Firstly, numerous challenges have still to be faced if patient-centred care for elderly patients with prostate cancer is to be improved (Droz et al. 2010, 2017; Jha et al. 2014). Indeed, medical literature qualifies prostate cancer care for elderly men as "defective" (Mongiat-Artus et al. 2009: 812). The paradox is striking: $45 \%$ of prostate cancer diagnoses occur in men aged over 75, yet treatments for older men are "unsuitable" (MongiatArtus et al. 2009) and scientific knowledge on the subject is lacking. Such gaps in knowledge can be attributed to the biomedical view of old age, which considers the elderly as a deteriorating, homogeneous group. Other factors, such as the existence of age limits for inclusion in clinical trials (often set at 65), stymie the development of therapies for the elderly. Moreover, elderly people tend to prioritise short-term quality of life over possibly increasing their life expectancy, which leads them to delay consulting a doctor immediately when symptoms arise, which may happen quite slowly (Mongiat-Artus et al. 2009).

Observations made within different healthcare facilities show that oncogeriatry has been integrated into care practices to a greater or lesser extent, depending on the hospitals and services in question. An observation made during a multidisciplinary meeting aimed at deciding upon the best therapeutic strategy for a patient was consistent with the finding that care of very elderly men continues to face certain significant challenges:

A urologist presented the case of a patient aged 81, to whom he had recently announced a prostate cancer diagnosis. Firstly, several characteristics of this man's cancer were listed (tumour stage, PSA levels, etc.). Next, the patient's general condition was collectively discussed. During these exchanges, an oncologist asked the urologist responsible for the patient whether he had carried out an ONCODAGE. This is a screening tool 
that, using just a few questions, allows identification of the vulnerabilities of an elderly person and then to guide those who are most vulnerable towards an oncological geriatrics appointment. The urologist admitted to not knowing what ONCODAGE was. The Head of the Urology Department added that he never used this tool but ultimately offered to make it available within his department.

(Field diary, regional hospital, 30/07/2013)

As this scenario shows, the movement aimed at integrating the elderly into medical discourse and practice has yet to fully accomplish its aims. Ageism continues to affect the care patients receive. Historian Kampf has also argued that the emphasis placed by medical discourse in recent years on young men with prostate cancer has indirectly contributed to the re-marginalisation of the oldest patients (Kampf 2013).

Secondly, numerous challenges remain to be faced to improve patient-centred care for gay and bisexual men with prostate cancer (Ussher et al. 2016). Few studies have examined the impact of prostate cancer on gay and bisexual men (Quinn et al. 2015). However, the results of two such studies show a higher rate of dissatisfaction and a more impaired quality of life after treatment than among heterosexual men (Hart et al. 2014; Torbit et al. 2015). These studies also claim that health professionals fail to take the concerns of gay and bisexual men into account, when managing prostate cancer. Moreover, the medical frames of reference, as well as numerous writings designed to inform patients and their loved ones, fail to address the particularities of a homosexual man's prostate cancer experience (Blank 2005; Dowsett 2008; Filiault et al. 2008). Although homosexual practices are increasingly accepted, they remain potentially stigmatisable. For gay and bisexual men, the process of coming out may be especially difficult because prostate cancer affects older people and places them in direct contact with a medical institution that has yet to prove its openness towards sexual minorities (Gustafsson et al. 2017; Sabin et al. 2015).

Finally, the objective of offering person-centred care for prostate cancer patients is confronted with limitations that are, in part, related to the difficulty of understanding masculinities in their plurality. To overcome this, Bullen and Tod encourage healthcare professionals "to find methods of support that, rather than imposing established more feminised perspectives, acknowledge and embrace masculine approaches to dealing with difficult situations" (Bullen \& Tod 2013: 11). 
International Journal of Ageing and Later Life

\section{Sexual health in prostate cancer care}

According to the literature, the sexual supportive care offer for prostate cancer patients seems to be better organised than it is for most other male cancers, or indeed for female cancers (Bondil \& Habold 2015; Flynn et al. 2012; Gilbert et al. 2016). The reason for this assertion lies mainly with the fact that prostate cancer impacts the genitals, and urologists are more attuned to questions tied to male sexuality. Gendered representations of sexuality also help explain the extra attention that men benefit from in this area.

The taboo around sexuality mentioned in previous studies on doctorpatient communication (Arrington 2004; Gray et al. 2000; Kunkel et al. 2000 ) is still very much present. Continued observation of medical consultations allows us to confirm that the subject of sexuality impacts the oldest patients most. Following a consultation with a man aged 82 years, a urologist told me that but for my presence he would not have asked the patient about his erections. His reaction, in addition to the expected ways in which the presence of a researcher changes a situation, revealed a difference in his practice, depending on the patient's age.

Sexual health in prostate cancer care can also be described as phallocentric (Tiefer 1996). Perception of sexuality is generally limited to the ability to have an erection. As it can be used almost systematically by some doctors, the international IIEF5 questionnaire - which serves to evaluate sexual function in five coded questions on a scale of 0-5 - is particularly representative of this biomedical vision of sexuality. In the context of this survey, only penetrative sexual acts are referred to. Other sexual practices are excluded (caresses, oral sex, kissing, masturbation, etc.). What is more, there is only one question that addresses the patient's satisfaction during sex. The other four questions seek to objectify the quality of the erection in terms of how long it lasts, and its rigidity.

The various solutions available to men to cope with erectile dysfunction are also based on a masculine sexual model. Viagra, Cialis, intracavernous injections, ${ }^{1}$ the vacuum pump or penile prosthesis all promise a quasi-mechanical erection, focusing sexuality even more on the penis,

${ }^{1}$ An intracavernous injection is an injection of a vasodilatator agent at the base of the penis. 
masculine desire and coital relations. Viagra, for example, has been described in various works as a medication that contributes to, reinforces and transforms male domination (Loe 2001; Mamo \& Fishman 2001; Potts et al. 2004). Even though Viagra can help build more positive attitudes towards the sexuality of the elderly, there is also a risk of conflating the injunction to "age well" with that of a performance-based, androcentric, heterosexual and penetrative sexuality (Potts et al. 2003).

These aids to achieving erection can, however, constitute real supports in the reappropriation of a diminished masculinity. Joël, for example, stated: "That's okay, I'm still a man" when he was able to return to achieving erections with the assistance of Cialis - a medication for erectile dysfunction. Nicolas said that he had been "reassured" when he began using intracavernous injections (Nicolas, aged 63, retired driver/deliveryman. Diagnosed in 2014, surgery). These technologies can also prove useful in the struggle against ageing (Gott \& Hinchliff 2011; Hurd Clarke \& Lefkowich 2018). Insofar as erectile dysfunction can be experienced as being tipped into very old age, using treatments to return to a certain level of "normality" - according to the terms used by several participants - does logically constitute a means of resistance to ageing.

The repercussions of prostate cancer on sexuality are also very often seen as an inevitability that is relatively well accepted because of ageing (Pietilä et al. 2018). "Had I been younger, perhaps it would have been more of a problem", as Léon put it (aged 78, retired postmaster. Diagnosed in 2008, radiotherapy, hormonotherapy). As Sandberg showed in her study with Swedish men (Sandberg 2016), sexual desire is frequently understood to vanish as one ages. The link between sexuality and youth is also often naturalised in patients' narratives, as in the example below:

To me, that's how life goes. Well... I had a great time when I was young, and the wheel has turned and that's all (laughter).

(Jean-François, aged 67, retired engineer. Diagnosed in 2012, surgery, hormonotherapy)

Most of the men for whom prostate cancer treatment had brought about lower libido as well as erectile and ejaculation problems also consider these consequences to be a lesser evil. For them, these are side effects that must be seen in relation to the risk of death posed by the cancer (Chapple \& Ziebland 2002: 831). 
International Journal of Ageing and Later Life

René: Yes, well it's all relative. [Sexuality] is one aspect, but at the moment, my real objective is recovery. [Sexuality] is a secondary consideration.

(René, aged 75, retired manager. Diagnosed in 2012, surgery)

Roland: My doctor said to me "Listen, sir, there are only two solutions, either we do nothing, and you continue getting your oats, and it probably won't last all that long, or I treat you and you probably won't be getting your oats, but I will extend your life expectancy and you'll get to enjoy your grandchildren".

Q.: He said that?

Roland: And I said to him, "I prefer my grandchildren to my oats".

(Roland, aged 65, retired estate agent. Diagnosed in 2012, radiotherapy, hormonotherapy)

Lastly, both the seriousness and the temporality of the illness play an important role in patient relationships to their physical limitations and rebuilding their sexuality. At the start of the care pathway, the question of sexuality is often secondary for patients and their loved ones because the fight against cancer is their top priority (Arrington 2003; Broom 2004; Oliffe 2005). During (and immediately after) treatment, organic limitations can be thought of as temporary, even if they turn out to be lasting. The hope of getting back to the state of health they had prior to the discovery of cancer often leads patients to approach the consequences of treatments like a hiatus in their trajectory. "The sexual and erection aspects, you say to yourself 'it's post-operative, it's normal to be like that'. It wasn't a priority, it didn't particularly bother me" (Martin, aged 64, retired airline pilot. Diagnosed in 2012, surgery, radiotherapy, hormonotherapy). Once patients are in remission or their health has stabilised, preoccupations about sexuality reappear more easily (Oliffe 2011 [2009]: 44).

\section{Conclusion}

In this article, we argue that combining the concept of hegemonic masculinity with an intersectional approach provides an appropriate theoretical framework for analysing the plurality of men's prostate cancer experience. This theoretical framework has allowed us to grasp the complexity between different masculinities. It has been particularly useful to analyse how gender and age are enmesh in the experience of prostate cancer. 
While there are numerous studies that examine the ways that different axes of power and difference intersect to affect health and well-being (Bauer 2014; Gkiouleka et al. 2018; Hankivsky 2012; Schulz \& Mullings 2006), rarely intersectionality has been applied to discuss the experience of illness or impairment among men. In our point of view, combining the concept of hegemonic masculinity with intersectionality is not only a useful tool for exploring the power relations inherent in construction of masculine identities and to bring attention to sexism, but also other systems of oppression and domination such as racism, ageism, classism, ableism and homophobia. Furthermore, this theoretical framework may also be useful for understanding how men embody the prevailing codes of masculinity according to their individual, sexual, age, racial and class variation when they are affected with very different illnesses. As O'Brien and his colleagues point out (2007), much can be gained from comparing prostate cancer with depression or heart disease among men.

Four steps of the patient care process were studied: screening, diagnosis, treatment and follow-up care. This has allowed us to show that throughout the patient care process, systems of oppression and privilege overlap and shape men's experience. However, each stage of a patient's trajectory involves specific power dynamics. Prostate cancer screening was examined first. We argue that PSA testing serves to sort those men who are at risk from those who are not, through the use of a statistical assessment of the body that originates at the intersection of the sex, age, race and family history risk factors. By studying male resistance to the digital rectal examination, we have also shown the crucial importance of repositioning the experience of this examination within the gender order in which it takes place while avoiding isolating it from other power relations. Next, the cancer diagnosis itself was addressed. At the level of cancer institutions, we argue that age and gender shape the announcement protocol and limit its implementation for prostate cancer patients. We have also called into question the disruptive nature of a prostate cancer diagnosis and shown the benefits of an attentive approach to the intersection of power relations. Lastly, our analysis has focused on the treatment and supportive care available to prostate cancer patients. We have shown that the objective of providing personcentred care for prostate cancer patients is complicated by the difficulty of understanding masculinities in their plurality. Supportive care 
International Journal of Ageing and Later Life

aimed at easing the effects of treatment on patient sexuality has also been described as embedded within systems of inequality.

The four stages of prostate cancer management that we have chosen to study show the full extent to which power relations can shape men's experience, from prevention through to post-treatment. However, they do not allow us to account for the full complexity of pathways in response to this illness. Firstly, other dimensions of prostate cancer management or turning points have yet to be investigated. End-of-life care, for example, has not been discussed in this article, even though several studies have already shown the benefits of questioning this stage via a reflection on gender and masculinities (Broom 2012; Broom \& Cavenagh 2010). Secondly, our analysis of the four different stages of prostate cancer management was never intended to report on the temporal aspects of the process of care. The dynamics of patient trajectories are still, therefore, in the shadows. Descriptions of how power relations impact individual health, and how men manage prostate cancer, remain areas of research rich in potential for further exploration.

\section{Acknowledgements}

I am grateful to the study participants who shared their experiences with me, as well as the health professionals who facilitated and supported this project. Thanks also for the instructive comments of two anonymous reviewers at the International Journal of Ageing and Later Life, and to Jane Roffe for her help in translating this article.

\section{Corresponding Author}

Louis Braverman, LEDa-LEGOS, Université Paris-Dauphine, Place du Maréchal de Lattre de Tassigny, 75016 Paris, France. Email: louis.braverman@gmail.com

\section{References}

Arrington, M. I. (2000). Sexuality, society, and senior citizens: An analysis of sex talk among prostate cancer support group members. Sexuality and Culture 4(4): 45-74. 
Arrington, M. I. (2003). "I don't want to be an artificial man": Narrative reconstruction of sexuality among prostate cancer survivors. Sexuality and Culture 7(2): 30-58.

Arrington, M. I. (2004). To heal or not to heal?: On prostate cancer, physician-patient communication, and sexuality. Journal of Loss and Trauma 9(2): 159-66.

Arrington, M. I. (2008). Prostate cancer and the social construction of masculine sexual identity. International Journal of Men's Health 7(3): 299-306.

Austin, J. L. (1975). How to do Things with Words. 2nd ed. Cambridge: Harvard University Press.

Balmer, C., Griffiths, F. \& Dunn, J. (2015). A "new normal": Exploring the disruption of a poor prognostic cancer diagnosis using interviews and participant-produced photographs. Health 19(5): 451-472.

Bauer, G. R. (2014). Incorporating intersectionality theory into population health research methodology: Challenges and the potential to advance health equity. Social Science \& Medicine 110: 10-17.

Bensig, J. (2000). Bridging the gap. The separate worlds of evidence-based medicine and patient-centered medicine. Patient Education and Counseling 39(1): 17-25.

Blank, T. O. (2005). Gay men and prostate cancer: Invisible diversity. Journal of Clinical Oncology 23(12): 2593-2596.

Blank, T. O. \& Bellizzi, K. M. (2008). A gerontologic perspective on cancer and aging. Cancer 112(11): 2569-2576.

Bondil, P. \& Habold, D. (2015). Développement de l'oncosexualité et oncofertilité en France: Aspects culturels et psychosociologiques [Development of oncosexuality and oncofertility in France: Why now? Cultural and psychosociological aspects]. Psycho-oncologie 9(4): 230-239.

Bourdieu, P. (1998). La domination Masculine [Masculine domination]. Paris: Seuil.

Broom, A. (2004). Prostate cancer and masculinity in Australian society: Acase of stolen Identity? International Journal of Men's Health 3(2): 73-91.

Broom, A. \& Cavenagh, J. (2010). Moralities, masculinities and caring for the dying. Social Science and Medicine 71(5): 869-876.

Broom, A. (2012). Gender and end-of-life care. In E. Kuhlmann \& E. Annandale (eds.) The Palgrave Handbook of Gender and Healthcare (pp. 224-238). London: Palgrave Macmillan. 
International Journal of Ageing and Later Life

Bullen, K. \& Tod, D. (2013). Men and masculinity: Understanding the challenges for urological cancer. Trends in Urology \& Men's Health 4(4): 9-12.

Bury, M. (1982). Chronic illness as a biographical disruption. Sociology of Health and Illness 4(2): 167-182.

Calasanti, T. M. (2003). Theorizing age relations. In S. Biggs, A. Lowenstein \& J. Hendricks (eds.) The Need for Theory: Critical Approaches to Social Gerontology (pp. 199-218). Amityville, NY: Baywood.

Calasanti, T., Pietilä, I., Ojala, H. \& King, N. (2013). Men, bodily control, and health behaviors: The importance of age. Health Psychology 32(1): 15-23.

Calasanti, T. M. \& Slevin, K. F. (eds.) (2006). Age Matters: Re-Aligning Feminist Thinking. New York: Routledge.

Cecil, R., McCaughan, E. \& Parahoo, K. (2010). “It's hard to take because I am a man's man": An ethnographic exploration of cancer and masculinity. European Journal of Cancer Care 19(4): 501-509.

Chapple, A. \& Ziebland, S. (2002). Prostate cancer: Embodied experience and perceptions of masculinity. Sociology of Health and Illness 24(6): 820-841.

Christensen, A.-D. \& Jensen S. Q. (2014). Combining hegemonic masculinity and intersectionality. NORMA 9(1): 60-75.

Collins, P. H. \& Bilge, S. (2016). Intersectionality. Cambridge: Polity Press.

Connell, R. W. (2005). Masculinities. Berkeley, CA: University of California Press. $2^{\text {nd }}$ ed. [1995]

Corbin, J. M. \& Strauss, A. (1988). Unending Work and Care: Managing Chronic Illness at Home. San Francisco, CA: Jossey-Bass.

Crawford, R. (1980). Healthism, and the medicalization of everyday life. International Journal of Health Services 10(3): 365-388.

Dale, W., Sartor, S., Davis, T. \& Bennett, C. L. (1999). Understanding barriers to the elderly detection of prostate cancer among men of lower socioeconomic status. Prostate Journal 1(4):176-184.

Demetriou, D. Z. (2001). Connell's concept of hegemonic masculinity: A critique. Theory and Society 30(3): 337-361.

Devreux, A. M. (1997). Des appelés, des armes et des femmes: l'apprentissage de la domination masculine à l'armée [Girls, guys and guns: Teaching Male Domination in the army]. Nouvelles Questions Féministes 18(3/4): 49-78.

Douglas, M. (1966). Purity and Danger: An Analysis of Concepts of Pollution and Taboo. London: Routledge. 
Droz, J. P., Balducci, L., Bolla, M., Emberton, M., Fitzpatrick, J. M., Joniau, S., Kattan, M. W., Monfardini, S., Moul, J. W., Naeim, A., van Poppel, H., Saad, F. \& Sternberg, C. N. (2010). Background for the proposal of SIOG guidelines for the management of prostate cancer in senior adults. Critical Reviews in Oncology/Hematology 73(1): 68-91.

Droz, J. P., Albrand, G., Gillessen, S., Hughes, S., Mottet, N., Oudard, S., Payne, H., Puts, M., Zulian, G., Balducci, L. \& Aapro, M. (2017). Management of prostate cancer in older men: Recommendations of a working group of the International Society of Geriatric Oncology. European Urology 74(4): 521-531.

Dowsett, G. W. (2008). "Losing my chestnut": One gay man's wrangle with prostate cancer. Reproductive Health Matters 16(32): 145-150.

Evans, R., Edwards A. G. K., Elwyn, G., Watson, E., Grol, R., Brett, J. \& Austoker, J. (2007). 'It's a maybe test': Men's experiences of prostate specific antigen testing in primary care. The British Journal of General Practice 57(537): 303-310.

Faulkner, A. (2010). Trial, trial, trial again: Reconstructing the gold standard in the science of prostate cancer detection. In C. Will \& T. Moreira (eds.) Medical Proof, Social Experiments: Clinical Trials in Shifting Contexts (pp. 137-152). Farnham: Ashgate.

Furlan, A. B., Kato, R., Vicentini F., Cury J., Antunes A. A. \& Srougi M. (2008). Patient's reactions to digital rectal examination of the prostate. International Brazilian Journal of Urology 35(5): 572-575.

Filiault, S., Drummond, M. \& Smith, A. (2008). Gay men and prostate cancer: Voicing the concerns of a hidden population. Journal of Men's Health 5(4): 327-332.

Flynn, K. E., Reese, J. B., Jeffery, D. D., Abernethy, A. P., Lin, L., Shelby, R. A., Porter, L. S., Dombeck, C. B. \& Weinfurt, K. P. (2012). Patient experiences with communication about sex during and after treatment for cancer. Psychooncology 21(6): 594-601.

Gilbert, E., Perz, J. \& Ussher, J. (2016). Talking about sex with health professionals: The experience of people with cancer and their partner. European Journal of Cancer Care 25(2): 280-293.

Gillespie, C. (2012). The experience of risk as "measured vulnerability": Health screening and lay uses of numerical risk. Sociology of Health $\mathcal{E}$ Illness 34(2): 194-207. 
International Journal of Ageing and Later Life

Gkiouleka, A., Huijts, T., Beckfield, J. \& Bambra, C. (2018). Understanding the micro and macro politics of health: Inequalities, intersectionality \& institutions - A research agenda. Social Science \& Medicine 200: 92-98.

Gott, M. \& Hinchliff, S. (2011). Sex and ageing: A gendered issue. In S. Arber, K. Davidson \& J. Ginn (eds.), Gender and Ageing. Changing Roles and Relationships (pp. 63-78). Philadelphia, PA: Open University Press.

Gray, R., Fitch, M., Phillips, C., Labrecque, M. \& Fergus, K. (2000). To tell or not to tell: Patterns of disclosure among men with prostate cancer. Psycho-Oncology 9(4): 273-282.

Gray, R., Fitch, M., Fergus, K., Mykhalovkiy, E. \& Church K. (2002). Hegemonic masculinity and the experience of prostate cancer: Narrative approach. Journal of Aging and Identity 7(1): 43-62.

Gray, R., Fergus, K. and Fitch, M. (2005). Two black men with prostate cancer: A narrative approach. British Journal of Health Psychology 10(1): $71-84$.

Grosclaude, P., Belot, A., Daubisse Marliac, L. \& Remontet, N. (2015). Le cancer de la prostate, évolution de l'incidence et de la mortalité en France entre 1980 et 2011 [Prostate cancer incidence and mortality trends in France from 1980 to 2011]. Progrès en Urologie 25(9): 536-542.

Grummet, J. P., Plass, K. \& N’Dow, J. (2017). Prostate cancer management in an ageing population. European Urology 72(4): 532-533.

Gustafsson, P. E., Linander, I. \& Mosquera, P. A. (2017). Embodying pervasive discrimination: A decomposition of sexual orientation inequalities in health in a population-based cross-sectional study in Northern Sweden. International Journal for Equity in Health 16(1): 22-32.

Hankivsky, O. (2012). Women's health, men's health, and gender and health: Implication of intersectionality. Social Science \& Medicine 74(11): 1712-1720.

Hart, T. L., Coon, D. W., Kovalkowski, M. A., Zhang, K., Hersom J. I., Goltz, H. H., Wittmann, D. A. \& Latini, D. M. (2014). Changes in sexual roles and quality of life for gay men after prostate cancer: Challenges for sexual health providers. The Journal of Sexual Medicine (9): 2308-2317.

Hurd Clarke, L. \& Lefkowich, M. (2018). "I don't have any issue with masculinity": Older Canadian men's perceptions and experiences of embodied masculinity. Journal of Aging Studies 45: 18-24. 
INCa. (2014). La vie deux ans après un diagnostic de cancer. De l'annonce à l'après-cancer [Life two years after a cancer diagnosis. From annoncement to post-cancer], Boulogne-Billancourt: INCa.

INCa. (2017). Les cancers en France, édition 2016 [Cancers in France, 2016 edition], Boulogne-Billancourt: INCa.

Jefferson, T. (2002). Subordinating hegemonic masculinity. Theoretical Criminology 6(1): 63-88.

Jha, G. G., Arnan, V., Soubra, A. \& Konety, B. (2014). Challenges of managing elderly men with prostate cancer. Nature Review Clinical Oncology 11(6): 354-364.

Kampf, A. (2013). "There is a person here" Rethinking ag(ing), gender and prostate cancer. In A. Kampf, B. Marshall \& A. Petersen (eds.), Aging Men, Masculinities and Modern Medicine (pp. 52-67). New York: Routledge.

Kelly, D. (2009). Changed men: The embodied impact of prostate cancer. Qualitative Health Research 19(2): 151-163.

Kenerson, D. (2010). Use of the Theory of Planned Behavior to Assess Prostate Cancer Screening Intent among African American Men. PhD dissertation in nursing science. Vanderbilt University. Available on https://pdfs. semanticscholar.org/9d72/0c0b2b4293b248394ace5a8e466c8b3d79ce. pdf (Accessed: October 26, 2019)

Kunkel, E., Bakker, J., Myers, R., Oyesablun, O. \& Gomella, L. (2000). Biopsychosocial aspects of prostate cancer. Psychosomatics 41(2): 85-94.

Liamputtong, P. \& Suwankhong, D., (2015). Breast cancer diagnosis: Biographical disruption, emotional experiences and strategic management in Thai women with breast cancer. Sociology of Health $\mathcal{E}$ Illnes 37(7): 1086-1101.

McMullin, J. A. \& Marshall, V. W. (2001). Ageism, age relations, and garment industry work in Montreal. The Gerontologist 41(1): 111-122.

Macias, D. J., Sarabia, M. J. \& Sklar, D. P, (2000). Male discomfort during digital rectal examination: Does examiner gender make a difference? American Journal of emergency Medicine 18(6): 676-678.

Nagler, H. M., Gerver E. W., Homel, P., Wagner, J. R., Norton, J., Lebovitch, S. \& Phillips, J. L. (2005). Digital rectal examination is barrier to populations-based prostate cancer screening. Urology 65(6): 1137-1140.

Loe, M. (2001). Fixing broken masculinity: Viagra as a technology for the production of gender and sexuality. Sexuality and Culture 5(3): 97-125. 
International Journal of Ageing and Later Life

Mamo, L. \& Fishman, J. R. (2001). Potency in all the right places: Viagra as a technology of the gendered body. Body \& Society 7(4): 13-35.

Mongiat-Artus, P., Peyromaure, M., Richaud, P., Droz, J. P., Rainfray, M., Jeandel, C., Rebillard, X., Moreau, J. L., Davin, J. L., Salomon, L., Soulié, M. \& les membres du sous- comité prostate du CC-AFU (2009). Recommandations pour la prise en charge du cancer de la prostate chez l'homme âgé: un travail du comité de cancérologie de l'association française d'urologie [Recommendations for the treatment of prostate cancer in the elderly man: A study by the oncology committee of the French association of urology]. Progrès en urologie 19(11): 810-817.

Noone, J. H. \& Stephens, C. (2008). Men, masculine identities, and health care utilization. Sociology of Health $\mathcal{E}$ Illness 30(5): 711-725.

O'Brien, R., Hart, G. J. \& Hunt K. (2007). "Standing out from the herd": Men renegotiating Masculinity in Relation to their experience of illness. International Journal of Men's Health 6(3): 178-200.

Oliffe, J. L. (2005). Construction of masculinity following prostatectomy-induced impotence. Social Science and Medicine 60(10): 2240-2259.

Oliffe, J. L. (2006). Embodied masculinity and androgen deprivation therapy. Sociology of Health $\mathcal{E}$ Illness 28(4): 410-432.

Oliffe, J. L. (2007). Men, masculinities, and prostate cancer: Australian and Canadian patient perspectives of communication with male physicians. Qualitative Health Research 17(2): 149-161.

Oliffe, J. L. (2011). Positioning prostate cancer as the problematic third testicle. In A. Broom and P. Tovey (eds.), Men's Health and Illness. Body, Identity and Social Context (2nd ed., pp. 33-62). West Sussex: Wiley-Blackwell.

Oliffe, J. L., Gerbrandt, J. S., Bottorff, J. L. \& Hislop, T. G. (2010). Health promotion and illness demotion at prostate cancer support groups. Health Promotion Practice 11(4): 562-571.

Parent, M. C., Hammer, J. H., Bradstreet, T. C., Schwartz, E. N. \& Jobe, T. (2018). Men's mental health help-seeking behaviors: An intersectional analysis. American Journal of Men's Health 12(1): 63-73.

Pietilä, I., Jurva, R., Ojala, H. \& Tammela, T. (2018). Seeking certainty through narrative closure: Men's stories of prostate cancer treatments in a state of liminality. Sociology of Health and Illness 40(4): 639-653. 
Potts, A., Gavey, N., Grace, V. M. \& Vares, T. (2003). The downside of Viagra: Women's experiences and concerns. Sociology of Health \& Illness 25(7): 697-719.

Potts, A., Grace, V., Gavey, N. \& Vares, T. (2004). "Viagra stories": Challenging "erectile dysfunction." Social Science \& Medicine 59(3): 489-499.

Quinn, G. P., Sanchez, J. A., Sutton, S. K., Vadaparampil, S. T., Nguyen, G. T., Green B. L., Kanetsky, P. A. \& Schabath, M. B. (2015). Cancer and lesbian, gay, bisexual, transgender/transexual, and queer/questioning (LGBTQ) populations. CA: A Cancer Journal for Clinicians 65(5): 384-400.

Rivas, C., Matheson, L., Nayoan, J., Glaser, A., Gavin, A., Wright, P. \& Watson, E. (2016). Ethnicity and the prostate cancer experience: A qualitative metasynthesis. Psychooncology 25(10): 1147-1156.

Rozet, F., Hennequin, C., Beauval, J. B., Beuzeboc, P., Cormier, L., Fromont, G., Mongiat-Artus, P., Ouzzane, A., Ploussard, G., Azria, D., BrenotRossi, I., Cancerl-Tassin, G., Cussenot, O., Lebret, T., Rebillard, X., Soulié, M., Renard-Penna, R. \& Méjean, A. (2016). Recommandations en onco-urologies 2016-2018 du CCAFU Cancer de la prostate [CCAFU French national guidelines 2016-2018 on prostate cancer]. Progès en Urologie 27(1): 95-143.

Sabin, J. A., Riskind, R. G. \& Nosek, B. A. (2015). Health care providers' implicit and explicit attitudes toward lesbian women and gay men. American Journal of Public Health 105(9): 1831-1841.

Sandberg, L. (2016). In lust we trust? Masculinity and sexual desire in later life. Men and Masculinities 19(2): 192-208.

Schaepe, K. S. (2011). Bad news and first impressions: Patient and family caregiver accounts of learning the cancer diagnosis. Social Science and Medicine 73(6): 912-921.

Schulz, A. J. \& Mullings, L. (Eds.) (2006). Gender, Race, Class, \& Health: Intersectional Approaches. San Francisco, CA: Jossey-Bass.

Stansbury, J. P., Mathewson-Chapman, M. \& Grant, K. E. (2003). Gender schema and prostate cancer: Veterans' cultural model of masculinity. Medical Anthropology 22(2): 175-204.

Tao, Z. Q., Shi, A. M., Wang, K. Z. \& Zhang, W. D. (2015). Epidemiology of prostate cancer: Current status. European Review for Medical and Pharmacological Sciences 19(5): 805-12. 
International Journal of Ageing and Later Life

Tiefer, L. (1996). The medicalization of sexuality: Conceptual, normative, and professional issues. Annual Review of Sex Research 7(1): 252-282.

Terret, C., Albrand, G. \& Droz, J. P. (2004). Geriatric assessment in elderly patients with prostate cancer. Clinical Prostate Cancer 2(4): 236-240.

Torbit, L. A., Albiani J. J., Crangle. C. J., Latini, D. M. \& Hart, T. L. (2015). Fear of recurrence: The importance of self-efficacy and satisfaction with care in gay men with prostate cancer. Psychooncology 24(6): 691-698.

Tuppin, P., Leboucher, C., Dougé, M., Peyre-Lanquar, G., Gabach, P., Descotes, J. L. \& Rebillard, X. (2016). Dépistage individuel du cancer de la prostate chez les hommes de 40 ans et plus, France, 2009-2015. Données du système national d'information inter-régimes de l'assurance maladie [Individual prostate cancer screening in men aged 40 and over, France, 2009-2015. Data from the national health insurance inter-schemes information system]. Bulletin épidémiologique hebdomadaire 39-40: 700-706.

Tronto, J. (1993). Moral Boundaries. A Political Argument for an Ethic of Care. New York: Routledge.

Ussher, J. M., Perz, J., Kellett, A., Chambers, S., Latini, D., Davis, I. D., Rose, D., Dowsett, G. W. \& Williams, S. (2016). Health-related quality of life, psychological distress, and sexual changes following prostate cancer: A comparison of gay and bisexual men with heterosexual men. The Journal of Sexual Medicine 13(3): 425-434.

Vassy, K. \& Keller, R. (2008). Faut-il contrôler les aspects éthiques de la recherche en sciences sociales et comment?. Mouvements 3-4(55-56): 128-141.

Wall, D. \& Kristjanson, L. (2005). Men, culture and hegemonic masculinity: Understanding the experience of prostate cancer. Nursing Inquiry 12(2): 87-97.

Wenger, L. \& Oliffe, J. (2014). Men managing cancer: A gender analysis. Sociology of Health and Illness 36(1): 108-122.

Wetherell, M. \& Edley, N. (1999). Negotiating hegemonic masculinity: Imaginary positions and psycho-discursive practices. Feminism and Psychology 9(3): 335-356.

Zanchetta Santos, M., Cognet, M., Xenocostas, S., Aoki, D. \& Talbot, Y. (2007). Prostate cancer among Canadian men: A transcultural view. International Journal of Men's Health 6(3): 224-258. 